\title{
Prenatal growth and risk of occlusive and haemorrhagic stroke in Swedish men and women born 1915-29: historical cohort study
}

\author{
E Hyppönen, D A Leon, M G Kenward, H Lithell
}

Evidence for an inverse association of impaired fetal growth with stroke is less securely established than that with coronary heart disease. Even less is known about the association of fetal growth with occlusive stroke and haemorrhagic stroke.

\section{Participants, methods, and results}

The cohort comprises all 14611 births in the Uppsala Academic Hospital between 1915 and 1929.' Socioeconomic circumstances and neonatal characteristics, including gestational age (number of completed weeks since last menstrual period), were available for $96 \%$ of the subjects from hospital records and follow up is $98 \%$ complete. Analyses were restricted to singletons born available in the 1960 and 1970 censuses. Data on occurrence of first stroke were obtained from the Swedish national hospital discharge register ${ }^{2}$ and from the national cause of death register. Two subtypes of stroke were defined-haemorrhagic (ICD-8 (international classification of diseases, 8th revision) 430-431; ICD-9 430-432) and occlusive (ICD-8 432-436; ICD-9 433-436). Each participant was considered at risk from the time of the 1970 census to date of first stroke, emigration, death, or end of follow up (31 December 1996).

The 10853 men and women had 991 first strokes-156 haemorrhagic, 775 occlusive, and 60 ill defined. Death certificates identified $41(26 \%)$ first haemorrhagic strokes and $17(2 \%)$ occlusive strokes. Of haemorrhagic strokes, 21 (13\%) were subarachnoid and $135(87 \%)$ intracerebral or unspecified intracranial haemorrhages. at 30-45 weeks' gestation for whom information was
Cox proportional hazards model showed birth weight inversely associated with risk of haemorrhagic stroke and little evidence of association with occlusive stroke. Hazard ratio per $1 \mathrm{~kg}$ increase in birth weight (adjusted for sex and period of birth) was 0.61 (95\% confidence interval 0.45 to 0.83 ) for haemorrhagic stroke and 0.89 (0.77 to 1.03) for occlusive stroke. Adjustment for socioeconomic factors at birth and at the time of the 1960 and 1970 censuses had little effect on estimates (table). When head circumference and birth length were adjusted for separately and in combination, the inverse association between birth weight and haemorrhagic stroke strengthened but there was little effect on the association of birth weight with occlusive stroke. Adjustment for gestational age had no substantive effect on the estimates.

\section{Comment}

Impaired fetal growth is strongly associated with haemorrhagic stroke, but not with occlusive stroke. This finding is consistent with results from a smaller cohort of Finnish men. ${ }^{3}$ The strength of the association between impaired fetal growth and haemorrhagic stroke is appreciably greater than that found with coronary heart disease in the same Swedish cohort. ${ }^{1}$ The associations were not accounted for by socioeconomic confounding factors, and they were not affected by adjustment for gestational age.

The inverse association of size at birth with haemorrhagic stroke in the Finnish cohort was apparent only after adjustment for head circumference, and this was interpreted as showing an association between stroke and in utero "head sparing." We found a

\section{Department of Paediatric Epidemiology and Biostatistics, Institute of Child Health, London WC1N 1EH Elina Hyppönen research fellow \\ Department of Epidemiology and Population Health, London School of Hygiene and Tropical Medicine, London \\ WC1E 7HT \\ David A Leon professor of epidemiology Mike G Kenward professor of \\ Department of Public Health and Caring Sciences, Geriatrics, \\ University of Uppsala, Uppsala SE-751 25, Sweden Hans Lithell professor of geriatrics Correspondence to: D A Leon david.leon@ \\ lshtm.ac.uk}

BMJ 2001;323:1033-4

Adjusted hazard ratios (95\% confidence interval) for haemorrhagic and occlusive stroke according to birth weight in Swedish men and women born between 1915 and 1929*

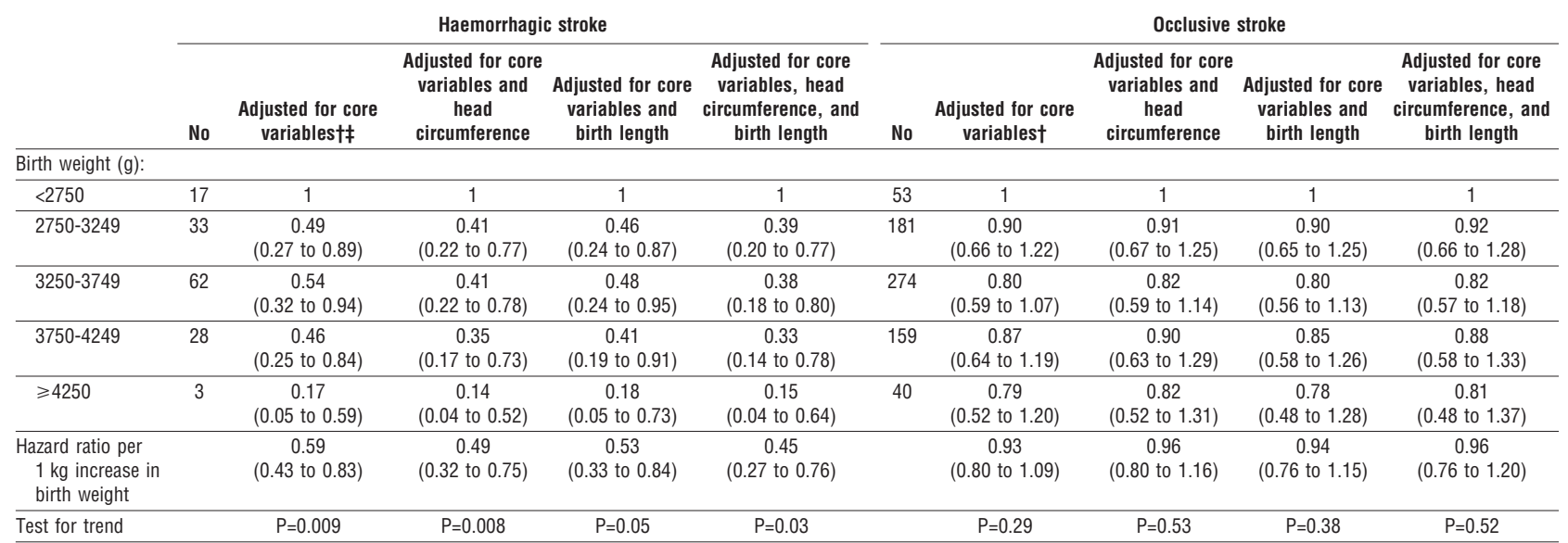

*Analyses restricted to $n=10009$ subjects with information available for all the variables in each stage of modelling †Core variables=sex, period of birth, and social trajectory.

¥Social trajectory consists of parental social characteristics (mother's civil status and social group) and indicators of participant's own social status in adulthood (social group, car ownership from 1960 census, education, income, and car ownership from 1970 census). 
pronounced inverse association with birth weight without adjustment for other birth dimensions, and adjustments for both birth length and head circumference strengthened the association with haemorrhagic stroke. These data do not support a special role for birth weight relative to head size, but they suggest that the risk of haemorrhagic stroke is related to impaired growth of soft tissue mass relative to bone growth. ${ }^{4}$

The established aetiology of stroke differs by subtype, although hypertension is an important risk factor for occlusive and haemorrhagic stroke. Raised blood pressure is also associated with impaired fetal growth. ${ }^{5}$ However, whether the difference between stroke subtypes in the strength of the association of stroke with birth weight is mediated by blood pressure has yet to be established.

We thank Rawya Mohsen for managing the study database.

Contributors: EH and DL wrote the paper. EH carried out the analyses. MGK acted as the statistical expert in the study, and
HL contributed with his knowledge of the cohort and stroke. DL had the original study idea and will act as the guarantor of the paper.

Funding: The Uppsala birth cohort study was established using grants from the UK Medical Research Council and the Swedish Council for Social Research. No funding was received towards the study.

Competing interests: None declared.

1 Leon DA, Lithell HO, Vågerö D, Koupilová I, Mohsen R, Berglund L, et al. Reduced fetal growth rate and increased risk of death from ischaemic heart disease: cohort study of 15000 Swedish men and women born 1915-29. BMJ 1998;317:241-5

2 National Board of Health and Welfare, Sweden. Hospital discharge register. http://www.sos.se/epc/par/pareng.htm (accessed 20 July 2001).

3 Eriksson JG, Forsen T, Tuomilehto J, Osmond C, Barker DJ. Early growth, adult income, and risk of stroke. Stroke 2000;31:869-74.

4 Leon DA, Johansson M, Rasmussen F. Gestational age and growth rate of foetal mass are inversely associated with systolic blood pressure in young adults: an epidemiologic study of 165,136 Swedish 18-year old men. AmJ Epidemiol 2000;152:597-604.

5 Huxley RR, Shiell AW, Law CM. The role of size at birth and postnatal catch-up growth in determining systolic blood pressure: a systematic review of the literature. J Hypertens 2000;18:815-31.

(Accepted 10July 2001)

\section{Unnecessary school absence after minor injury: case-control study}

Peter M Barnes, Lorna Price, Alison Maddocks, Ronan A Lyons, Pam Nash, Michael McCabe

Department of Community Child Health, Swansea NHS Trust, Central Clinic, Swansea SA1 1LT

Peter M Barnes specialist registrar Lorna Price staff grade doctor Alison Maddocks consultant

Department of Public Health, Iechyd Morgannwg Health Authority, Swansea SA1 1LT Ronan A Lyons senior lecturer

Local Accident Centre, Neath

General Hospital,

Neath SA11 2LQ

Pam Nash

consultant

Accident and

Emergency

Department,

Swansea NHS

Trust, Morriston

Hospital, Swansea

SA6 6NL

Michael McCabe

consultant

Correspondence to:

A Maddocks

alison.maddocks@

swansea-tr.wales.

nhs.uk

BMJ 2001;323:1034-5
Children acquire many of the academic and social skills they need for their adult lives at school. Excessive absence from school is associated with educational failure, particularly when children miss more than $11 \%$ of school days. ${ }^{1}$ Each year, one in three British children goes to an emergency department for treatment, predominantly with minor injuries, but the effect on school attendances has not been quantified. ${ }^{2}$

This study was designed to investigate the number of days missed from school after children attended one of three local emergency departments with minor injuries. We defined minor injuries as those not requiring admission to hospital and not affecting mobility or the ability of the child to care for himself or herself.

\section{Method and results}

This case-control study involved children resident in, and attending school full time in, the Welsh counties of Swansea and Neath Port Talbot during the autumn school term of 1999. A case was defined as a child who attended the local emergency department on a Sunday preceding a school week with an injury that should not prevent school attendance. The children and their families were not informed of inclusion in the study. The next child of the same sex on the class register was chosen as a matched control. Ethical approval was obtained from Morgannwg Local Research Ethics Committee.

For each case, we obtained the age, sex, home postcode, school attended, and nature of the injury from the emergency department's records. School attendance for each half day in the week that followed the injury was recorded from the school register for the case pupil and the matched control (along with the
Relation between minor injuries and subsequent school attendance in pupils in full time education in two Welsh counties

\begin{tabular}{lcc} 
Injury & $\begin{array}{c}\text { Number (\%) of } \\
\text { injuries }\end{array}$ & $\begin{array}{c}\text { Mean (range) number of } \\
\text { half days }\end{array}$ \\
\hline Bruise & $115(27)$ & $7.9(0-10)$ \\
\hline Sprain & $110(26)$ & $7.1(0-10)$ \\
\hline Laceration & $66(16)$ & $6.7(0-10)$ \\
\hline Fracture & $57(14)$ & $5.5(0-10)$ \\
\hline Head injury & $28(7)$ & $7.8(0-10)$ \\
\hline Puncture wound & $9(2)$ & $7.3(0-10)$ \\
\hline Bite & $8(2)$ & $6.9(0-10)$ \\
\hline Abrasion & $7(2)$ & $8.0(2-10)$ \\
\hline Nasal injury & $7(2)$ & $6.9(1-10)$ \\
\hline Eye injury & $6(1)$ & $8.7(4-10)$ \\
\hline Burn/scald & $5(1)$ & $6.0(0-10)$ \\
\hline Foreign body & $3(1)$ & $9.3(8-10)$ \\
\hline Haemarthrosis & $1(<1)$ & 0 \\
\hline All & 422 & $7.4(0-10)$ \\
\hline
\end{tabular}

${ }^{\star}$ Tissue injury such as from a splinter or metal fragment.

control pupil's home postcode). For a randomly chosen sample of 100 pairs, we recorded the school attendance for each half day in the school week that preceded the minor injury.

Differences in school attendance between the matched pairs were analysed by using the one sample $t$ test and Wilcoxon's matched pairs signed ranking test. A Townsend small area deprivation score was calculated for each child, and the children's attendances were analysed in relation to these scores. ${ }^{3}$

Overall, 422 case-control pairs were identified in 130 schools; 251 (59\%) pairs comprised boys. Ages ranged from 4 to 16 years (mean 10.6 years). The type and frequency of injury were recorded along with the mean number of half days present in school for each injury type (table). 